\title{
User Experience Design of Stroke Patient Communications Using Mobile Finger (MOFI) Communication Board With User Center Design Approach
}

\author{
https://doi.org/10.3991/ijim.v12i2.7937 \\ Aan Jelli Priana $\left.{ }^{\bowtie}\right)$, Herman Tolle, Ismiarta Aknuranda \\ Faculty of Computer Science Brawijaya University Malang, Jawa Timur, Indonesia \\ ms.aanjp@gmail.com \\ Eko Arisetijono \\ Brawijaya University Malang, Jawa Timur, Indonesia
}

\begin{abstract}
Stroke has become a phenomenon in Indonesia. From 2014 to mid-2015, the disease is the first cause of death in Indonesia. This is of particular concern to the Ministry of Health so that the prevention, treatment, and prevention of stroke is further enhanced. The condition of stroke patients whose movements are limited is exacerbated by the psychic condition of patients who are unable to communicate pressure will cause obstacles to the healing process of the patient. This research proposes a stroke patient communication media by applying the technology of Mobile Finger Communication Board and user center design approach (UCD). This communication board is operated using the patient's fingers so that it is comfortable for everyday activities. Mobile Finger Communication Board Design based on five planes of user experience. The result of Mobile Finger Communication Board implementation shows that application usability level seen from perception and ergonomic point of view shows satisfaction index of the user at the satisfactory level so that it can be said that the system works with the satisfactory result of the users. It is expected that with a convenient Mobile Finger Communication Board can support the healing process of stroke so that the healing rate of stroke is increasing.
\end{abstract}

Keyword-User Experience, Stroke, Communication Board, Activity of Daily Living, User Center Design.

\section{Introduction}

Stroke has become a phenomenon in Indonesia. In the 1990s, stroke was the fourth leading cause of death. However, in 2014 until mid-2015, this disease became the first cause of death in Indonesia. This is of particular concern to the Ministry of Health so that the prevention, treatment, and prevention of stroke are further enhanced. [1]

Looking at the trend of stroke that occurs, it is necessary to prevent and to handle stroke well. In general, prevention efforts are done from the diet, rest, and exercise. 
While the stroke treatment is done through treatment to hospital, polyclinic and traditional herbal medicine. The percentage of healing stroke is dependent on the condition of stroke. Also, perseverance, tenacity and the willingness of patients to heal also contributed the percentage of healing stroke.

The condition of heavy stroke patients who can not speak, limited movement and even paralysis will cause their own barriers for patients, families and outpatient treatment processes to the hospital. The condition of stroke is exacerbated by the psychic condition of the pressure of the patient who is unable to communicate, unable to walk even dependent by the family member or caregiver causing the stroke handling to belong. Therefore, it needs support to the condition of the stroke patient so that the treatment and healing process can run smoothly so that the healing rate of stroke is increasing.

Support for severe stroke patients who are unable to communicate, can not walk, paralyzed and dependent on family members or caregivers can be through the procurement of a tool to assist the communication activities of stroke patients. Research says that communication boards have been proven to reduce frustration with communication. Patients have specific ideas about what terms and ideograms are useful for communication boards. A communication board is effective in reducing frustration and in facilitating communication. More specifically some advantages of communication boards are improving the efficiency and speed of communication, facilitating needs, and facilitators to gain recognition of patient individuality [2].

There is a technology outside the field of health but can support health and provide a positive influence of mobile technology. Mobile technology can support health services beyond the scope of the hospital for chronic and degenerative diseases [3]. Mobile technology can also be used for people with disabilities where they can not talk and use their hands to control an app. Implementation of mobile technology is located on Head Movement Controller System (HEMOCS) [4]. HEMOCS implements a new customized keyboard layout design based on the alphabet usage frequency in English and Range of Motion (ROM) to observe reactions from HEMOCS users [5].

Based on the need for stroke and stroke patients support, in this research a communication media of stroke patients, especially patients with difficulty speaking conditions is proposed, limbs are difficult to move and require the help of others. This research applies human-computer interaction (HCI) technology and Mobile Finger (MOFI).

This study was used to help non-verbal communication of stroke patients so that patients and people around can do daily activities well. With better communication then the information will be well received. The use of communication boards with the help of the patient's finger swipe does not complicate the limitations of patient movement so that it is comfortable to use for every day and the process of healing or stroke recovery can run smoothly. Use of communication board with the help of a patient's fingers or tap. This is because stroke patients have limited motor movement and can only move their fingers only.

Communication board design applies the principle of user experience which process is divided into five areas: strategy, scope, structure, skeleton, surface. Also, 
this communication board design using User Center Design (UCD) method is a usercentered interface design concept method with the conclusion from the user experience through efficient observation [6]. From the previous description, the purpose of this study is to design a communication board for non-verbal communication media of stroke patients, apply communication board usage in stroke patients and analyze communication board performance from usability side of stroke patients.

\section{$1 \quad$ Literature Review}

\subsection{Communication board}

A communication board is a board used to communicate, especially for patients with certain diseases. In this communication, a board is provided features that represent some of the daily activities of the patient. One example of the communication board shown in Figure 2 below is the Vidatak EZ Board communication board, which was patented in the United States in 1999.

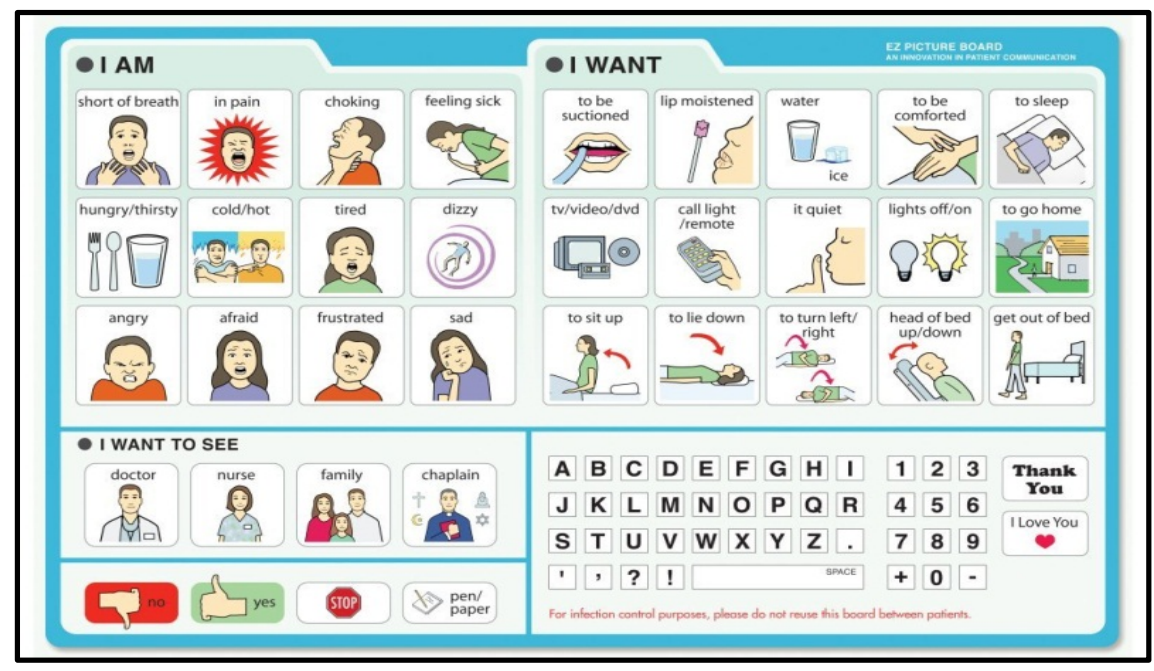

Fig. 1. Communication Board Vidatak

The illustration of the board shows the existence of four important parts, each of which has some icons that represent the actions of a particular patient. These four sections include the "I AM" section indicating the patient's current state, then the "I WANT" section indicating the desired request by the patient, the "I WANT TO SEE" section indicating the patient's desire to meet with someone, and finally is the "KEYBOARD" section where the patient can designate a number of characters, either alphabetically or numerically as a patient's misspelled means to be understood by others. 


\subsection{Activity daily living (ADL)}

Activity Daily Living is an activity doing daily routine work. ADL is an essential activity for self-care. ADL includes among others: toilets, eating, dressing (dressing), bathing, and moving places [9]. Activity Daily Living are the basic skills and occupational duties that must be possessed by a person to take care of himself independently of a person's daily work to fulfill or relate to his role as a person in the family and society[10]. Figure 2 shows about activity daily living.

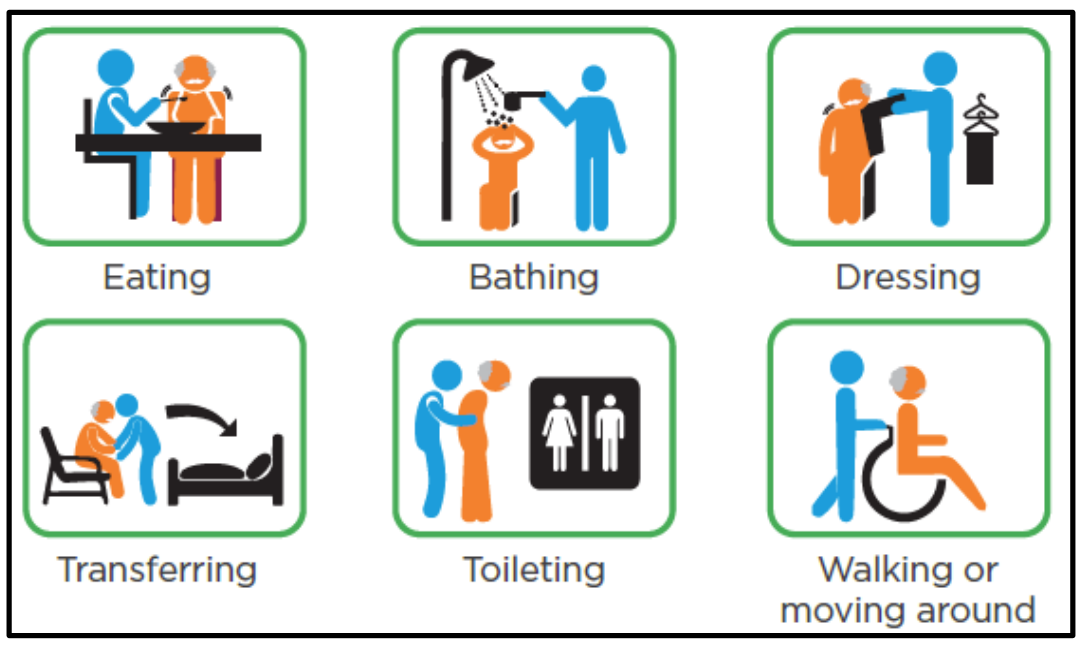

Fig. 2. Activity Daily Living

\subsection{Stroke}

Stroke is a condition that occurs when the blood supply to the brain is cut off due to blockage or rupture of blood vessels, resulting in the death of cells in some areas of the brain. Stroke is a serious health condition that requires rapid treatment [8]. Aphasia is a syndrome of the nervous system (neurological) that impairs the ability of language. People who suffer from this disease will have difficulty in expressing the mind and finding it difficult to understand and find words while communicating. Of course, this will cause problems in the life of the sufferer. Therefore, communication is one of the important things in life. Usually, this disease will occur suddenly after you have a stroke or injury to the head. Aphasia is divided into three nonfluent aphasia (people who experience the disease will communicate using incomplete sentences but can understand what others are saying), fluent aphasia (people who experience this type of aphasia can speak fluently, using long sentences, complex, and often unreasonable and unable to comprehend the spoken language of the other person well), global aphasia (occurs when the language network of the brain has been severely damaged and widespread so that the sufferer will experience severe disability in terms of understanding and expression). Based on these three types of aphasia, the study used a patient belonging to nonfluent aphasia or motoric aphasia. 


\subsection{User experience (UX) and user center design (UCD)}

According to Jakob Nielsen, user experience encompasses all aspects of user interaction with the company, its services, and its products. User Experience (UX) is an experience made by a product to people as its users in the real world [6]. UX is not simply a chain of work within the product or service that is the main thing in the product. User Experience (UX) focuses more on functions outside the product when in direct contact or contact with the user. The design used in this study is the method of analysis by using The Five Planes based on research [6] about user experience. The user experience development process is all the processes that ensure the user understands every action taken and understands the user's expectation for each action to be performed. The user experience development process is divided into five areas namely strategy, scope, structure, skeleton, and surface. The user experience development process is done from the bottom up.

The user-centered design method is a user-centered, user-centered design conceptual method with a conclusion from the user experience through efficient observation. The interface design process focuses more on usability objectives, user characteristics, tasks, and workflows in interface design. All information obtained through analysis of habits through a survey. The analysis results are then processed so that the design decisions obtained interface design user-friendly. [6]

According to ISO 13407, UCD Process describes a general process for humancentered activities in the development cycle. The human-centered design process for interactive systems. There are four processes in UCD (ISO 13407: 1999) there are understand and define user context, determine the needs of users and organizations, the resulting design solution, evaluation of the design of the needs of users

\section{Design of Mobile Finger (MOFI) Communication Board}

Mobile Finger Communication Board will generally refer to the daily needs of everyday users or Activity Daily Living which represents some daily activities that are always done eating, bathing, wearing clothes, moving places, to the toilet and walking the streets. In addition to referring activity daily living or daily activities, this application also refers to the Health Communication Board created by the VIDATAK company called EZ Picture Board. In the MOFI, there is also a menu to represent the feelings or something that complained of the user that is pain, dizziness, cold, heat, fear and sadness. When a user selects an action he or she wants, the system will play the sound of the selected action through the speakers on the device. In addition to selecting the action, the user can also compose a word consisting of a certain number of characters. If he makes a mistake in entering a character, he can delete the character. The user can also play the sound of the word he has compiled through the speakers on the device.

Respondents were selected based on Purposive sampling technique with the qualification of the respondent test is respondent have aphasia complaint due to the history of stroke disease; respondent has experience using a mobile device, respondent can read picture or writing (not illiterate). From these qualifications, the 
Paper-User Experience Design of Stroke Patient Communications Using Mobile Finger (MOFI)...

selected test respondents are the users with aphasia complaints due to stroke diseases both male and female, amounting to 10 people. Data collection is done through interviews and observation. The interview was conducted to a neurologist at a hospital, as a source who knew about stroke as well as doctors who deal with stroke patients. Also, interviews were also conducted to ten patients in each home, accompanied by family members and conditioned as comfortable as possible according to the instructions of a neurologist. Observations or observations are made on stroke patients who are implementing communication boards using a single finger touch (tap), double-tap double touch, and swipe to the right and left. Duration of interview and observation for each patient \pm 30 - 45 minutes.

The data collected is then analyzed using a user experience process consisting of five steps (the five planes), namely strategy analysis, scope, structure, skeleton, and surface. Followed by the analysis using user design method which consists of understanding and determining the user context, determining the needs of users and organizations, resulting in design solutions, design evaluation of user needs, data collection and observation.

\subsection{Functional Requirement Analysis}

System functional requirements are necessities that represent what things the system can do. The functional requirements are shown in Table 1.

Table 1. Functional Requirement

\begin{tabular}{|c|c|l|}
\hline No. & Req. Code & \multicolumn{1}{|c|}{ Functional Requirement } \\
\hline 1. & SRS-MCB-01 & $\begin{array}{l}\text { The system provides daily life menu choices and complaints to be com- } \\
\text { municated by actors. }\end{array}$ \\
\hline 2. & SRS-MCB-02 & $\begin{array}{l}\text { If the actor selects a particular action, the system must be able to play the } \\
\text { sound of the action through the device. }\end{array}$ \\
\hline 3. & SRS-MCB-03 & $\begin{array}{l}\text { The system provides a keyboard to use for typing the word as the actor } \\
\text { wishes. }\end{array}$ \\
\hline 4. & SRS-MCB-04 & $\begin{array}{l}\text { If the actor decides to play the word sound he has compiled, then the } \\
\text { system must be able to play the word sound through the device. }\end{array}$ \\
\hline 5 & SRS-MCB-05 & $\begin{array}{l}\text { Actors can replace or delete characters that have been typed on the system } \\
\text { keyboard board }\end{array}$ \\
\hline
\end{tabular}

The identifiable system actor is the user who has the limitation in communicating due to an illness. People who have normal physical conditions are also included in the category of system users. While actions that actors can take against the system include selecting the board/tap menu, hearing the sound of the selected menu, typing words on the keyboard, playing word sounds, and deleting characters.

\subsection{Non Functional Requirement Analysis}

The purpose of the analysis of non-functional needs is to get a specification about quality aspects required by the application. The result of non-functional requirement 
analysis of system development Design User Experience Media Communication of Stroke Patients as shown in Table 1. The non-functional requirement is shown in Table 2 below:

Table 2. Non Functional Requirement

\begin{tabular}{|c|l|}
\hline Non Functional Requirement & \multicolumn{1}{c|}{ Description } \\
\hline Usability & $\begin{array}{l}\text { Applications should be easy to use with a minimum usability level } \\
\text { satisfactory }(61-80 \%)\end{array}$ \\
\hline
\end{tabular}

\subsection{Scope Design}

The scope design or scope of the Mobile Finger Communication Board consists of several content needs that must be met. The content will be the viewing menu in the Mobile Finger Communication Board application and according to the user's needs of basic human needs (ADL), the usual complaints submitted by the patient, the patient's desire to meet someone, the patient's desire for entertainment / refreshment, patient ("Yes", "No", "OK", "Thank You").

\subsection{Structure Design}

In the design of structures, interaction design and information architecture are created. The structure field serves to determine the direction of navigation in an application and relates to the content available on the pre-made scope design. The structure design of the Mobile Finger Communication Board consists of several structures shown in Figure 4 below:

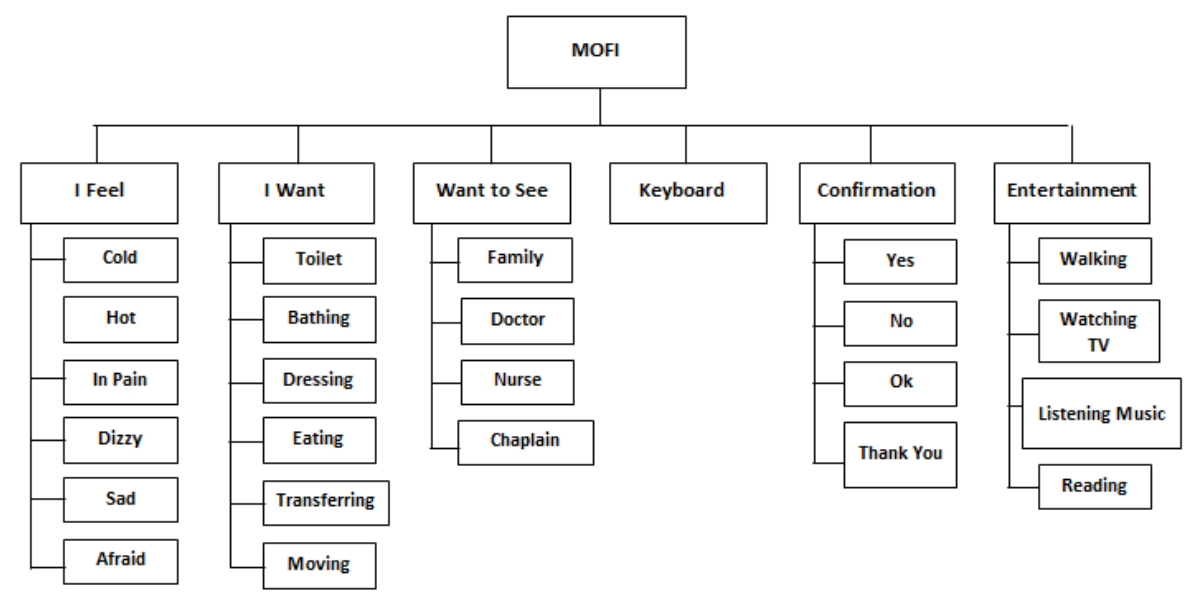

Fig. 3. Scope Design MoFi Communication Board 


\subsection{Skeleton Design}

Skeleton design is more emphasis on setting the location of elements. The following is shown in Figure 5 is one of the skeleton designs in the main menu Mobile Finger Communication Board :

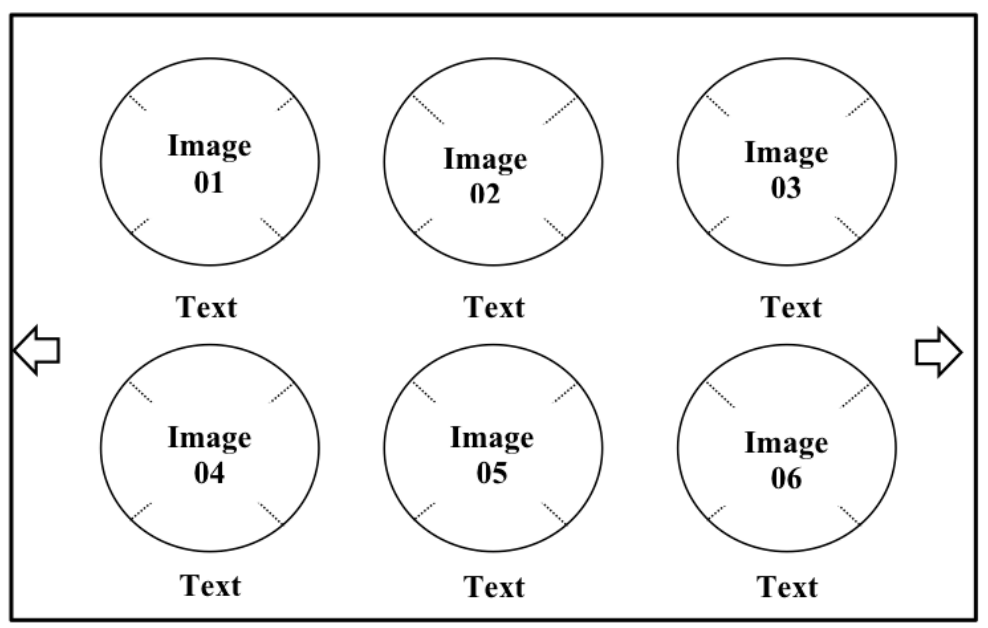

Fig. 4. Skeleton Design of MoFi Communication Board Main Menu

\subsection{Interface Design}

One design of the Mobile Finger Communication Board interface is shown in Figure 6 below:

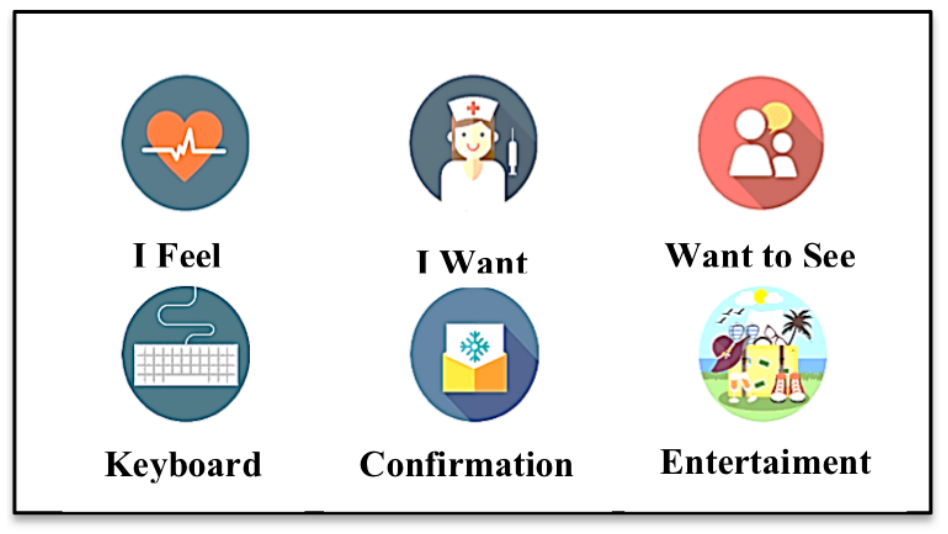

Fig. 5. Interface Design of Main Menu 
Paper-User Experience Design of Stroke Patient Communications Using Mobile Finger (MOFI)...

\subsection{Control Design}

The type of interaction that the user performs on the system is the type of interaction that is mediated interaction (mediated interaction) is done by using gesture movement (gesture). The action that can be done by the user against the system, among others, select the menu with a tap, shift the cursor arrow position of the page, choose a specific action, choose characters to compose a word, replace and delete characters. When a user is inside a certain page, he can move to the page position before and afterward by tapping the movements of his fingers or shifting (swipe) the screen with the touch of a finger.

\subsection{Screenflow Design}

Screenflow is a term that can be used to describe the flow of interfaces that occur within a system. There are eight screen displays which consist of MoFi.Apk Application, main menu, "I feel" menu, "I want" menu, "want to meet" menu, "keyboard board" menu, "confirmation" menu, and "entertainment" menu. The eighth view is a view of the interface compiler of the system to be developed. After the main menu, the user can select other menus as desired, then also can make a choice back to the main menu.

\section{$4 \quad$ Implementation}

Implementation of the system discussed, among others, about the explanation of the system specification, the limits in implementing the software, the application of method and application of user interface. MoFi implementation is done using usercentered design method. The MOFI-controlled system is implemented into several mobile devices of different sizes: the first device (smallest size $=4$ inches), proceed to the second device (medium size $=5.3$ inches) and proceed to the third device (largest size $=7$ inches). The user's fingers touch the screen of the device once in a short time with a range of icon menu size. If the user uses a finger tap with a long touch time, then the voice response that appears will be too late. If the user uses double finger tap with long touch time or more than twice, then the system will be too late to respond to the sound. The user's finger shifts the screen (swipe) of the device once with the widest range of menu screen sizes just to slide to the right and to the left. When the user shifts up or down the system can not respond to the action. Sound processing on MoFi using Google Text to Speech. Figure 6, Figure 7 and Figure 8 show the view of the MoFi menus that are implemented on mobile devices: 
Paper-User Experience Design of Stroke Patient Communications Using Mobile Finger (MOFI)..
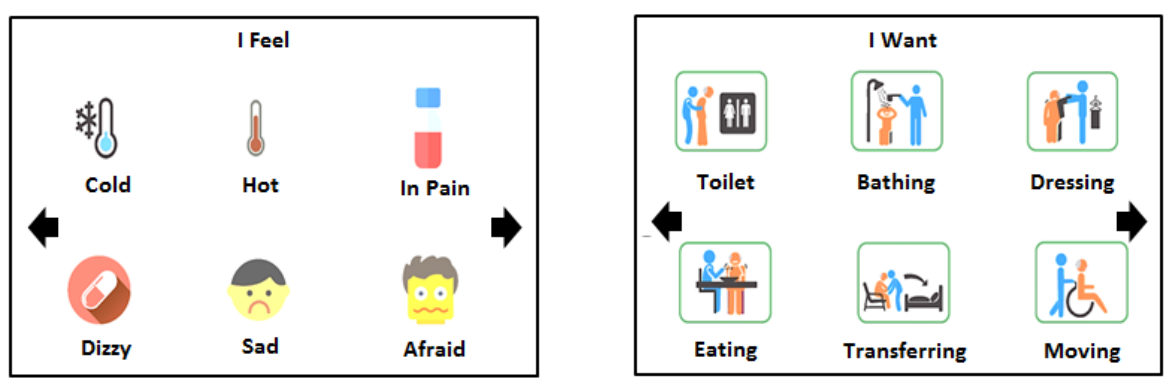

Fig. 6. Interface Design of "I Feel" and "I Want" Menu
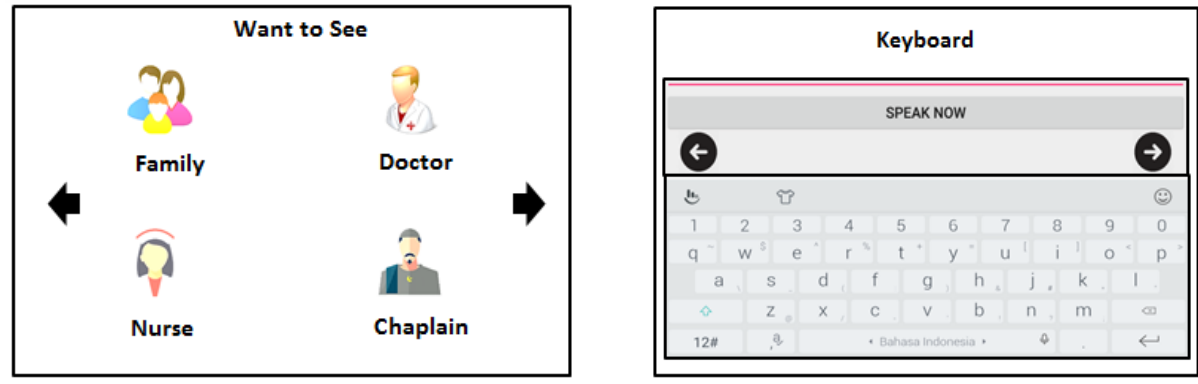

Fig. 7. Interface Design of "Want to See" and "Keyboard" Menu
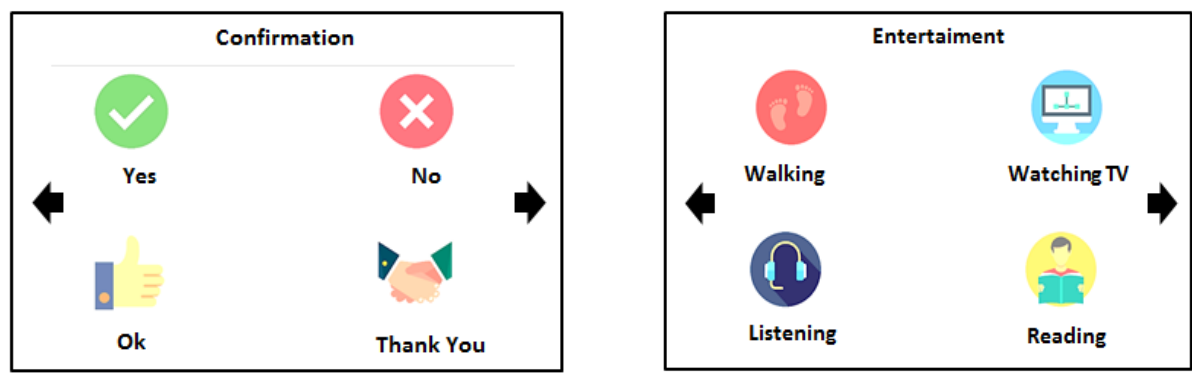

Fig. 8. Interface Design of "Confirmation" and "Entertainment" Menu
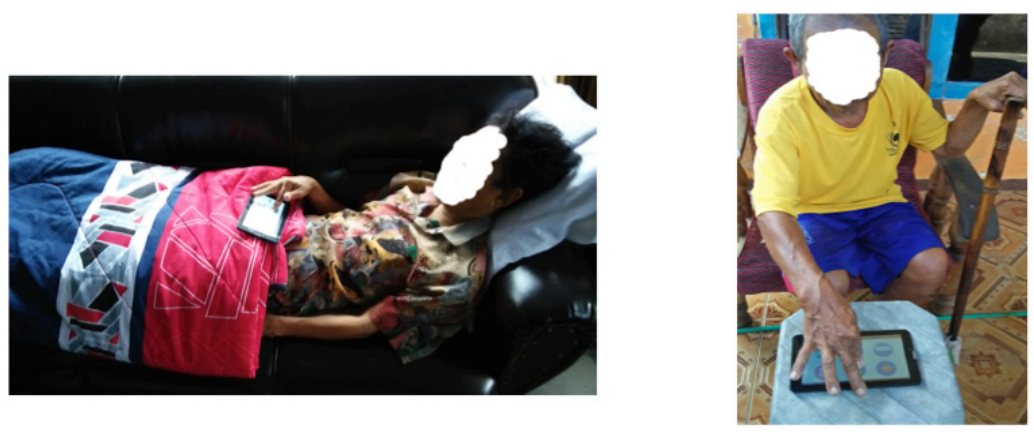

Fig. 9. Implementation Mobile Finger Communication Board 
Table 3. Demography of Respondents

\begin{tabular}{|c|c|}
\hline Respondents $=10$ & \\
\hline - Age & $>40$ th $=10$ and $<40$ th $=0$ \\
\hline - Gender & Female $=4$ and Male $=6$ \\
\hline - Work & $\begin{array}{ll}\text { Farmer }=5 & \text { Entrepreneur }=1 \\
\text { Employe }=2 & \text { Housewife }=2\end{array}$ \\
\hline - Long Occurrence of Stroke & $\begin{array}{l}>1 \text { year }=7 \\
<1 \text { year }=3\end{array}$ \\
\hline - Intensity of Mobile Device Use & $\begin{array}{l}\text { Often }(\geq 1 \mathrm{x} / \text { day }) \quad=9 \\
\text { Rarely }(\leq 1 \mathrm{x} / 3-7 \text { day })=1\end{array}$ \\
\hline
\end{tabular}

\subsection{Implementation of User Center Design (UCD) Method}

There are four processes in User Center Design (UCD) by ISO 13407:1999:

1. Understand and define user context. MOFI developed to help communication between users who have difficulty communicating (Aphasia) with people around due to stroke. This application will generally refer to Activity Daily Living (ADL). In this application, there is also a menu to represent the feelings or something that complained of the user that is pain, dizziness, cold, heat, fear and so on.

2. Determine the needs of users and organizations. The needs of MOFI users can be realized in the analysis of functional requirements and content requirements contained in Table 1.

3. The resulting design solution. MOFI application design is based on user experience design approach (UX) which consists of design strategy, scope design, structure design, skeleton design and surface design. The results of each design have been shown in section tree.

4. Evaluation of the design of the needs of users. Evaluation of the design is done when testing the application to the user. This evaluation was applied by trial to users (stroke patients and normal people) of 10 people and then recorded responses and user ratings using questionnaires.

\section{$5 \quad$ Evaluation}

The evaluation will be discussed about functional testing and nonfunctional testing. Functional testing is a test conducted to determine whether the system has been implemented by functional requirements that have been defined in the beginning. The system requirement to be used in this test comes from the functional requirements previously written in Table 1 . This functional testing method is done by using the black box, and functional requirement will be tested using some test cases. A good test case can represent all possible pathways that users can make to the system. From the test cases obtained results that the whole functional testing has been valid. This means the system has successfully done the task of switching positions, sound management, display images, and text. 
Non-functional testing is a test conducted to determine the quality and to the system that has been implemented. The parameters to be used in this non-functional testing process are device control parameters and usability parameters. MoFi control method uses fingers when choosing application menu. Based on the results of the control tests of each device then obtained a device control analysis that amounted to $74 \%$ for the device control score 1 , which is classified as a satisfaction category. While in device 2, obtained a control score of $75 \%$ classified as a satisfaction category, and on device 3 , obtained a score of control of $81 \%$ which classified the category is very satisfaction.

The next non-functional testing parameter is usability, which is the parameter used in testing the level of user satisfaction regarding the use of the system that has been developed. This test is done by testing the system that has been developed directly to some respondents. Respondents will be asked to fill out a questionnaire containing some statements related to the convenience and ease of use of the system. The statements to be used in this research questionnaire come from previous research titled "Toward Standard Usability Questionnaires For Handheld Augmented Reality" [11] where the research discusses usability measurements on the use of mobile device technology on android. Classification of questionnaire result consist of very unsatisfaction (0-20\%), not satisfaction (21-40\%), neutral (41-60\%), satisfaction (61$80 \%)$ and very satisfaction $(81-100 \%)$.

Table 4. Questionnaire

\begin{tabular}{|c|l|}
\hline No & \multicolumn{1}{|c|}{ List of Questionnaire Statement } \\
\hline \multicolumn{3}{|c|}{ Related Statement of Application Usage Perception Problem } \\
\hline 1. & I think the amount of information displayed on the mobile device screen is appropriate \\
\hline 2. & I think the information displayed on the device's screen is easy to read \\
\hline 3. & I think that the information displayed has a quick response \\
\hline 4. & I think the words and icons displayed on the device screen are easy to read \\
\hline 5. & I think the information displayed on the screen is consistent \\
\hline & \multicolumn{1}{|c|}{ Related Statement of Application Usage Ergonomic Issues } \\
\hline 6. & I think interacting with this app does not require much effort mentally \\
\hline 7. & I think interacting with this app does not require much physical effort \\
\hline 8. & I think the use of this application is convenient to use my finger \\
\hline 9. & I find it easy to input information through the application \\
\hline 10 & I do not feel my finger tired after using this app \\
\hline 11 & I think the operation of this application is simple and not complicated \\
\hline
\end{tabular}

The result of usability parameter test of each device shows that on the first device average usability is $73,6 \%$ (satisfaction category), on second device average usability is $75 \%$ (satisfaction category) and on third device average usability equal to $81.4 \%$ (very satisfaction category). Of the three devices, the satisfaction index on the user perception aspect shows the highest score in the first statement that "the amount of information displayed on the mobile device screen is appropriate." Then the satisfaction index on the aspect of ergonomics of the use of the application shows the highest 
Paper-User Experience Design of Stroke Patient Communications Using Mobile Finger (MOFI)...

score on the seventh statement is "about interaction with the application does not require much physical effort." The overall test results show that the developed system provides satisfaction results to the users.

Table 5. Experimental Result of Device 1,2 and 3

\begin{tabular}{|c|c|c|c|c|}
\hline NO & Usability & Device 1 & Device 2 & Device 3 \\
\hline 1 & User Perception & $73,2 \%$ & $76 \%$ & $80,8 \%$ \\
\hline 2 & Ergonomic & $74 \%$ & $74 \%$ & $81 \%$ \\
\hline \multicolumn{2}{r|}{ Total } & $73,6 \%$ & $75 \%$ & $81,4 \%$ \\
\hline \multicolumn{2}{|c|}{ Level of Usability } & Satisfaction & Satisfaction & Very Satisfaction \\
\hline
\end{tabular}

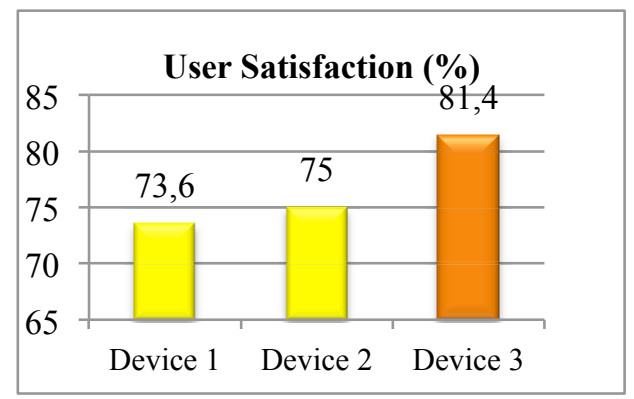

Fig. 10.Experimental Result of Usability

Analysis of these results indicates that more app users feel comfortable when using a third device that is a tablet-smartphone with a larger screen size ( 7 inches) of the first device ( 5 inches) and second (5.3 inches). The results indicate to the iterative that the greater the device, the more satisfaction. But from the aspect of practical use, if the device size is too large then the user will be more difficult and heavy to carry it. It can be said that for users, especially for patients, the use of applications on mobile devices can be tailored to the conditions, needs, and comfort of the patient. Mobile devices should not overload and reduce patient comfort.

\section{Conclusion}

This research proposes a stroke patient communication media by applying Mobile Finger Communication Board technology with user center design (UCD) approach. This communication board is operated using the patient's fingers so that it is comfortable for everyday activities. Mobile Finger Communication Board Design based on five planes of user experience. The tests performed are functional testing, control testing, device testing and non-functional testing or usability testing. The results of the implementation and testing show that the application usability level in the three devices viewed from the perspective of perception and ergonomics are at satisfaction levels (devices 1 and 2) and very satisfaction (device 3 ) so that it can be 
said that the developed system gives satisfaction results to the users. For further research to make this application more developed features and tested again using some parameters of other users satisfaction to more respondents and use a more varied device sizes for more optimal results. This research proposes a stroke patient communication media by applying Mobile Finger Communication Board technology with user center design (UCD) approach. This communication board is operated using the patient's fingers so that it is comfortable for everyday activities. Mobile Finger Communication Board Design based on five planes of user experience. The tests performed are functional testing, control testing, device testing and non-functional testing or usability testing. The results of the implementation and testing show that the application usability level in the three devices viewed from the perspective of perception and ergonomics are at satisfaction levels (devices 1 and 2) and very satisfaction (device 3) so that it can be said that the developed system gives satisfaction results to the users. For further research to make this application more developed features and tested again using some parameters of other users satisfaction to more respondents and use a more varied device sizes for more optimal results.

\section{$7 \quad$ References}

[1] Badan Penelitian dan Pengembangan Kesehatan, "Riset Kesehatan Dasar (RISKESDAS) 2013," Lap. Nas. 2013, pp. 1-384, 2013.

[2] L. Patak, A. Gawlinski, N. I. Fung, L. Doering, J. Berg, and E. A. Henneman, "Communication boards in critical care: patients' views," Appl. Nurs. Res., vol. 19, no. 4, pp. 182-190, 2006. https://doi.org/10.1016/j.apnr.2005.09.006

[3] F. Zhou, H. Yang, J. M. R. Álamo, J. S. Wong, and C. K. Chang, "Mobile Personal Health Care System for Patients with Diabetes," Architecture, pp. 94-101, 2010. https://doi.org/10.1007/978-3-642-13778-5 12

[4] H. Tolle and K. Arai, "Design of Head Movement Controller System ( HEMOCS ) for Control Mobile Application through Head Pose Movement Detection," pp. 24-28.

[5] H. Tolle, H. Tolle, I. Aknuranda, M. T. Ananta, K. C. Brata, and H. M. Az-Zahra, "Design of Keyboard Input Control for Mobile Application using Head Movement Control Design of Keyboard Input Control for Mobile Application using Head Movement Control ( HEMOCS )," no. October 2016.

[6] J. J. Garrett, THE ELEMENTS OF USER EXPERIENCE.

[7] M. Pantic, A. Nijholt, A. Pentland, and T. S. Huang, "Human-Centred Intelligent HumanComputer Interaction $\left(\mathrm{HCI}^{\wedge} 2\right)$ : how far are we from attaining it?," Int. J. Auton. Adapt. Commun. Syst., vol. 1, no. 2, pp. 168-187, 2008. https://doi.org/10.1504/IJAACS. 2008.019799

[8] H. Takao, Y. Murayama, T. Ishibashi, K. L. Karagiozov, and T. Abe, "A new support system using a mobile device (smartphone) for diagnostic image display and treatment of stroke," Stroke, vol. 43, no. 1, pp. 236-239, 2012. https://doi.org/10.1161/STROKE AHA.111.627943

[9] R. Best and P. Standards, "Area of Function: INSTRUMENTAL ACTIVITIES OF DAILY LIVING ( ADL )," no. September, pp. 1-6, 2004.

[10] W. Mojsa and S. Chlabicz, "Assessment and physical activities of daily living among patients under long-term home care nursing," vol. 5, no. 1, pp. 56-62, 2015.

[11] M. E. C. Santos, J. Polvi, T. Taketomi, G. Yamamoto, and C. Sandor, "Toward Standard Usability Questionnaires for Handheld Augmented Reality,” 2015. 
Paper-User Experience Design of Stroke Patient Communications Using Mobile Finger (MOFI)...

\section{Authors}

Aan Jelli Priana is a master student of the Faculty of Computer Science Brawijaya University, Malang, which takes the multimedia, games, and mobile.

Herman Tolle is a lecturer at the Faculty of Computer Science Brawijaya University, Malang for the field of the multimedia, games, and mobile.

Ismiarta Aknuranda is a lecturer at the Faculty of Computer Science Brawijaya University, Malang for the field of the information systems.

Eko Arisetijono is a specialist neurologist and lecturer at the Faculty of Medicine Brawijaya University Malang, East Java, Indonesia.

Article submitted 05 November 2017. Final acceptance 21 January 2018. Final version published as submitted by the authors. 